\title{
Notch1 suppresses prostate cancer cell invasion via the metastasis-associated 1-KiSS-1 metastasis-suppressor pathway
}

\author{
GANG DENG $^{1 *}$, XIAOLIANG ZHENG ${ }^{2 *}$, PEIWU JIANG $^{3 *}$, KEAN CHEN $^{3}$, XIAOJU WANG ${ }^{2}$, \\ KANG JIANG ${ }^{1}$, WENJUN ZHANG ${ }^{2}$, LINGLAN TU ${ }^{2}$, DONGMEI YAN ${ }^{2}$, LIBIN MA $^{4}$ and SHENGLIN MA ${ }^{5}$ \\ ${ }^{1}$ Department of Urology, Hangzhou First People's Hospital, Hangzhou, Zhejiang 310006; \\ ${ }^{2}$ Center for Molecular Medicine, Zhejiang Academy of Medical Sciences, Hangzhou, Zhejiang 310000; \\ ${ }^{3}$ Zhejiang Chinese Medical University and Hangzhou First People's Hospital; Departments of ${ }^{4}$ Nephrology \\ and ${ }^{5}$ Oncology, Hangzhou First People's Hospital, Hangzhou, Zhejiang 310006, P.R. China
}

Received March 20, 2016; Accepted February 14, 2017

DOI: $10.3892 / 01.2017 .6761$

\begin{abstract}
Notch1 is a type-1 transmembrane receptor which has been demonstrated to be involved in proliferation in various organisms. A number of studies have proposed that Notch signaling may be aberrantly activated, thus contributing to development, invasion and metastasis in a variety of human cancers. In the present study, the function and mechanism of Notch1 in human prostate cancer (PCa) LNCaP cells in vitro was investigated. Notch1 and cleaved-Notch1 expression were evaluated in human PCa cell lines, including LNCaP, PC-3 and DU 145, and the human prostate epithelial RWPE-1 cell line. LNCaP cells were transfected with Notch1-targeting short hairpin RNAs (shRNAs) and the level of proliferation, the ability to invade and the expression of genes associated with cancer cell invasion were subsequently investigated. Notch1 was highly expressed in LNCaP, PC-3 and DU 145 cells compared with RWPE-1 cells, while cleaved-Notch1 was expressed in LNCaP, PC-3 and DU 145 cells, and only to a minimal extent in RWPE-1 cells. Knockdown of Notch1 by shRNA in LNCaP cells markedly decreased cell invasion through Matrigel and inhibited cell proliferation $48 \mathrm{~h}$ following transfection. Reverse transcription-quantitative polymerase chain reaction analysis indicated that Notch1-knockdown resulted in a significant reduction of metastasis-associated 1 (MTA1) and increase of KiSS-1 metastasis-suppressor
\end{abstract}

Correspondence to: Dr Shenglin Ma, Department of Oncology, Hangzhou First People's Hospital, 261 Huansha Road, Hangzhou, Zhejiang 310006, P.R. China

E-mail:dfg326@yeah.net

Dr Libin Ma, Department of Nephrology, Hangzhou First People's Hospital, 261 Huansha Road, Hangzhou, Zhejiang 310006, P.R. China

E-mail: maryabc@163.com

*Contributed equally

Key words: Notch1, prostate cancer, metastasis-associated 1, KiSS-1 metastasis-suppressor
(KISS-1), mitogen-activated protein kinase 4 (MKK4) and cluster of differentiation 82 (KAI1). The present data demonstrated that expression of Notch1 was significantly associated with the invasion of prostate cancer. Knockdown of Notch1 decreased the invasive ability of LNCaP cells, which may be caused by downregulating MTA1 and upregulating KISS-1, MKK4 and KAI1. These findings indicated that targeting Notch1 may provide a novel method of suppressing or treating metastasis in prostate cancer.

\section{Introduction}

Among all major cancers, prostate cancer (PCa) has one of the worst prognoses; it was ranked 2 nd for cancer-associated mortality causes worldwide in 2012 (1). There is evidence to suggest that this may be due to carcinoma in the prostate being more inclined to metastasize (2). The lymph nodes and bone are the destination of metastatic cells in 70-80\% cases of prostate cancer-associated mortality (3). However, early stage diagnosis methods currently available for $\mathrm{PCa}$ are poor, and the lack of effective therapies for advanced carcinoma results in a high mortality rate among patients.

Notch1 is a type I transmembrane protein, which has a dual function of cell membrane surface receptors and nuclear transcription regulation (4). Previous studies have reported that the Notch signaling pathway may be aberrantly activated, contributing to the development, invasion and metastasis of a wide variety of human cancers, including cervical, lung, colon, head and neck, renal carcinoma, acute myeloid, Hodgkin and large-cell lymphomas and pancreatic cancer (5-7). Notch are a family of transmembrane proteins with epidermal growth factor-like domains. There are four Notch receptors (Notch-1 to -4 ), as well as six ligands (Jagged1 and 2 and d-like 1, 2, 3 and 4), in mammalian cells $(8,9)$. The signaling pathway is divided into an extracellular and intracellular region, the latter of which may be cleaved when the associated genes are expressed (10-12).

It is established that multiple steps are involved in the progression of metastasis in prostatic tumors, including angiogenesis, migration and intravasation, leading to tumor cell invasion and ultimately, metastasis (13). It has been reported 
that Notch signaling may regulate the metastasis of tumors in multiple tissues and organs (14-17). Therefore, in the present study, Notch1 was knocked down to investigate the function and mechanism of Notch1 in the invasion and metastasis of human PCa LNCaP cells in vitro.

\section{Materials and methods}

Cell culture. The human prostatic carcinoma LNCaP, PC-3 and DU 145 cell lines and the immortalized human prostatic epithelial RWPE-1 cell line were obtained from the American Type Culture Collection (Manassas, VA, USA). LNCaP, PC-3 and DU 145 cells were maintained in RPMI-1640 medium (Cellgro; Corning Life Sciences, Corning, NY, USA) supplemented with $10 \%$ fetal bovine serum (FBS; Biowest USA, Riverside, MO, USA). RWPE-1 cells were maintained in keratinocyte serum-free medium (Invitrogen; Thermo Fisher Scientific, Inc., Waltham, MA, USA). All cells were incubated in an environment of $5 \% \mathrm{CO}_{2}$ at $37^{\circ} \mathrm{C}$.

Western blot analysis. LNCaP, PC-3, DU 145 and RWPE-1 cells were collected and washed twice with cold PBS, and then lysed in radioimmunoprecipitation assay buffer (Beyotime Institute of Biotechnology, Jiangsu, China) containing the protease inhibitor phenylmethanesulfonyl fluoride, with mild sonication on ice. Cell lysates $(20 \mu \mathrm{g})$ were used for western blot analysis, subsequent to $11.5 \%$ SDS-PAGE, with primary antibodies against Notch1 (cat. no. 3608S), cleaved-Notch1 (cat. no. 4147S) and GAPDH (cat. no. 5174), and a secondary HRP-conjugated anti-rabbit IgG (cat. no. 7074S). All antibodies were used at a 1:2,000 dilution and were purchased from Cell Signaling Technology, Inc. (Danvers, MA, USA). Non-specific binding was blocked by incubating with tris-buffered saline with Tween-20 and 5\% skimmed milk powder for $60 \mathrm{~min}$ at room temperature. The membrane was incubated with the primary antibodies at $4^{\circ} \mathrm{C}$ overnight, then with the secondary antibody for $2 \mathrm{~h}$ at room temperature. The band intensities of the target proteins and GAPDH were quantified using Image Lab 5.0 software (Bio-Rad Laboratories, Inc., Hercules, CA, USA), and the intensity of each target protein was normalized to the corresponding GAPDH level.

RNA interference. In a 6-well tissue culture plate, LNCaP cells at $50-70 \%$ confluency in $800 \mu \mathrm{l}$ of short hairpin RNA (shRNA) plasmid transfection medium (cat. no. sc-108062) was transfected with $200 \mu$ l Notch 1 shRNA plasmid (cat. no. sc-36095-SH) or control shRNA plasmid-A/shRNA plasmid transfection reagent complex (cat. no. sc-108060), all from Santa Cruz Biotechnology, Inc. (Dallas, TX, USA). Following transfection for $24 \mathrm{~h}$ at $37^{\circ} \mathrm{C}$, RPMI medium was prepared containing twice the usual concentration of FBS $(20 \%)$ and antibiotics. A total of $1 \mathrm{ml}$ prepared medium was added to each well, and the cells were incubated for an another $24 \mathrm{~h}$ at $37^{\circ} \mathrm{C}$ with $5 \% \mathrm{CO}_{2}$. The medium was then replaced with RPMI with $10 \%$ FBS containing $10 \mu \mathrm{g} / \mathrm{ml}$ of puromycin. Every 2-3 days, medium was aspirated out and replaced with freshly prepared RPMI with $10 \%$ FBS. The cells were subsequently collected and processed for western blotting, reverse transcription-quantitative polymerase chain reaction (RT-qPCR), cell invasion and proliferation assays.
$R T-q P C R$. RNA was extracted from the cell lines using TRIzol (Thermo Fisher Scientific, Inc.). RNA (1-2 $\mu \mathrm{g}$ ) was reverse transcribed to cDNA using the Transcription First Strand cDNA Synthesis kit (Roche Diagnostics, Basel, Switzerland). qPCR analyses were performed using Fast Start Universal SYBR-Green Master (ROX; Roche Diagnostics) on the ABI 7500FAST system (Applied Biosystems; Thermo Fisher Scientific, Inc.) The thermocycling settings were as follows: An initial temperature of $95^{\circ} \mathrm{C}$ for $5 \mathrm{~min}$; then 35 cycles of $95^{\circ} \mathrm{C}$ for $15 \mathrm{sec}, 60^{\circ} \mathrm{C}$ for $60 \mathrm{sec}$, and $72^{\circ} \mathrm{C}$ for $60 \mathrm{sec}$; then a final extension step of $10 \mathrm{~min}$ at $72^{\circ} \mathrm{C}$. qPCR results for target gene expression were normalized using GAPDH as the internal control. Relative target gene expression levels normalized to GAPDH were determined with the formula $2^{-\Delta \mathrm{Cq}}$, in which $\Delta \mathrm{Cq}=\mathrm{Cq}_{\text {targetgene }}-\mathrm{Cq}_{\mathrm{GAPDH}}$. To calculate the fold changes of target gene expression in LNCaP cells transfected with Notch1 shRNA plasmid compared with the control cells, the $2^{-\Delta \Delta \mathrm{Cq}}$ method was used (17), in which $\Delta \Delta \mathrm{Cq}=\Delta \mathrm{Cq}_{\text {Notch1 shRNA }}-\Delta \mathrm{Cq}_{\text {cell control }}$, and $\log _{2}$ values were calculated. The sequences for primers used in the RT-qPCR assay, as supplied by Invitrogen (Thermo Fisher Scientific, Inc.) are listed in Table I. Invasion assay. Matrigel (BD Biosciences, Franklin Lakes, NJ, USA) was thawed at $4{ }^{\circ} \mathrm{C}$ overnight and then diluted 1:4 in serum free-cold cell culture media. Matrigel $(50 \mu 1)$ was added to the upper chambers of a 24-well Transwell plate, and the insert was gently rotated to ensure the entire membrane was coated. Subsequently, the Transwell was incubated at $37^{\circ} \mathrm{C}$ for $5 \mathrm{~h}$ for gelling and to absorb the residual liquid. LNCaP cells transfected with Notch1 shRNA plasmid or control shRNA plasmid-A were then starved for $24 \mathrm{~h}$ in serum-free RPMI containing $1 \%$ FBS, and cells from the tissue culture flasks were harvested using trypsin/EDTA. The cells were then washed once with serum-free RPMI, and resuspended in serum-free RPMI at a density of $1 \times 10^{6}$ cells $/ \mathrm{ml}$. A total of $100 \mu \mathrm{l}$ cell suspension was added to the Matrigel, the lower chamber of the Transwell plate was filled with $600 \mu 1$ cell culture media containing $10 \% \mathrm{FBS}$, and the plate was incubated at $37^{\circ} \mathrm{C}$ for $24 \mathrm{~h}$. Crystal violet dye (as $0.09 \%$ crystal violet in $10 \%$ ethanol) was then prepared and $500 \mu$ l dye was added to the empty wells. The chamber was moved with forceps into the dye well, incubated in the dye for $30 \mathrm{~min}$ at room temperature, washed in water for $\sim 5 \mathrm{sec}$, and the inner surface was then cleaned with a cotton swab to remove the dye that remained inside. Visual/qualitative observations were then made using a microscope at x100 magnification, and the numbers of invading cells were manually counted. All assays were performed in triplicate for 3 independent experiments.

Cell proliferation assay. Cell proliferation analysis was performed using the WST-1 assay, a colorimetric assay for the nonradioactive quantification of cell proliferation, cell viability and cytotoxicity (Roche Diagnostics), according to the manufacturer's protocol. Briefly, cells were plated on 96-well plates (5,000 cells/well) and cell viability was then determined.

Statistical analysis. Data were expressed as the mean \pm standard deviation. Statistical significance of the differences between groups was analyzed by one-way analysis of variance followed by Newman-Keuls multiple comparisons tests, 
Table I. Sequences for primers used for reverse transcription-quantitative polymerase chain reaction analysis.

\begin{tabular}{|c|c|}
\hline $\begin{array}{l}\text { Gene } \\
\text { symbol }\end{array}$ & Sequence \\
\hline Notch1 & $\begin{array}{l}\text { Forward 5'-GAGGCGTGGCAGACTATGC-3' } \\
\text { Reverse 5'-CTTGTACTCCGTCAGCGTGA-3' }\end{array}$ \\
\hline MTA1 & $\begin{array}{l}\text { Forward 5'-ACGCAACCCTGTCAGTCTG-3' } \\
\text { Reverse 5'-GGGCAGGTCCACCATTTCC-3' }\end{array}$ \\
\hline KISS-1 & $\begin{array}{l}\text { Forward 5'-AGCAGCTAGAATCCCTGGG-3' } \\
\text { Reverse 5'-AGGCCGAAGGAGTTCCAGT-3' }\end{array}$ \\
\hline MKK4 & $\begin{array}{l}\text { Forward 5'-TGAGAAGGGTGACTGCATCG-3' } \\
\text { Reverse 5'-ACCAAACCATTGACACCGAAG-3 }\end{array}$ \\
\hline KAI1 & $\begin{array}{l}\text { Forward 5'-TGTCCTGCAAACCTCCTCCA-3' } \\
\text { Reverse 5'-CCATGAGCATAGTGACTGCCC-3' }\end{array}$ \\
\hline GAPDH & $\begin{array}{l}\text { Forward 5'-GGCTGAGAACGGGAAGCTTGT } \\
\text { CAT-3' } \\
\text { Reverse 5'-CAGCCTTCTCCATGGTGGTGA } \\
\text { AGA-3' }\end{array}$ \\
\hline
\end{tabular}

MTA1, metastasis-associated 1; KISS-1, KiSS-1 metastasissuppressor, MKK4, mitogen-activated protein kinase 4; KAI1, cluster of differentiation 82 .

using SPSS 10.0 for windows (SPSS, Inc., Chicago, IL, USA). $\mathrm{P}<0.05$ was considered to indicate a statistically significant difference.

\section{Results}

Notchl and cleaved-Notchl are overexpressed in human PCa cells. It was previously reported that Notch signaling may markedly impact prostate development and disease (18). In the present study, western blot analysis was employed to detect Notch1 and cleaved-Notch1 expression in the human prostatic carcinoma cell lines LNCaP, PC-3 and DU 145 and the immortalized human RWPE-1 prostatic epithelial cell line. Notch1 was revealed to be highly expressed in LNCaP, PC-3 and DU 145 cells compared with RWPE-1 cells, while cleaved-Notch1 was expressed in LNCaP, PC-3 and DU 145 cells, and only to a minimal extent in RWPE-1 cells (Fig. 1).

Notch1-knockdown by shRNA in LNCaP cells. To address the involvement of Notch1 in PCa invasion, knockdown of Notch1 was achieved by transfecting LNCaP cells with Notch1 shRNA and scrambled control shRNA. RT-qPCR revealed Notch1-knockdown in cells transfected with Notch1 shRNA, but not in the non-transfected control cells or cells transfected with scrambled shRNA (Fig. 2). These results were verified by western blot analysis; Notch1 protein and cleaved-Notch1 expression were downregulated in cells transfected with Notch1 shRNA compared with non-transfected control cells or cells transfected with scrambled shRNA (Fig. 2).

Notch1-knockdown decreases invasion and proliferation of LNCaP cells. To examine the effects of Notch1-knockdown,
A
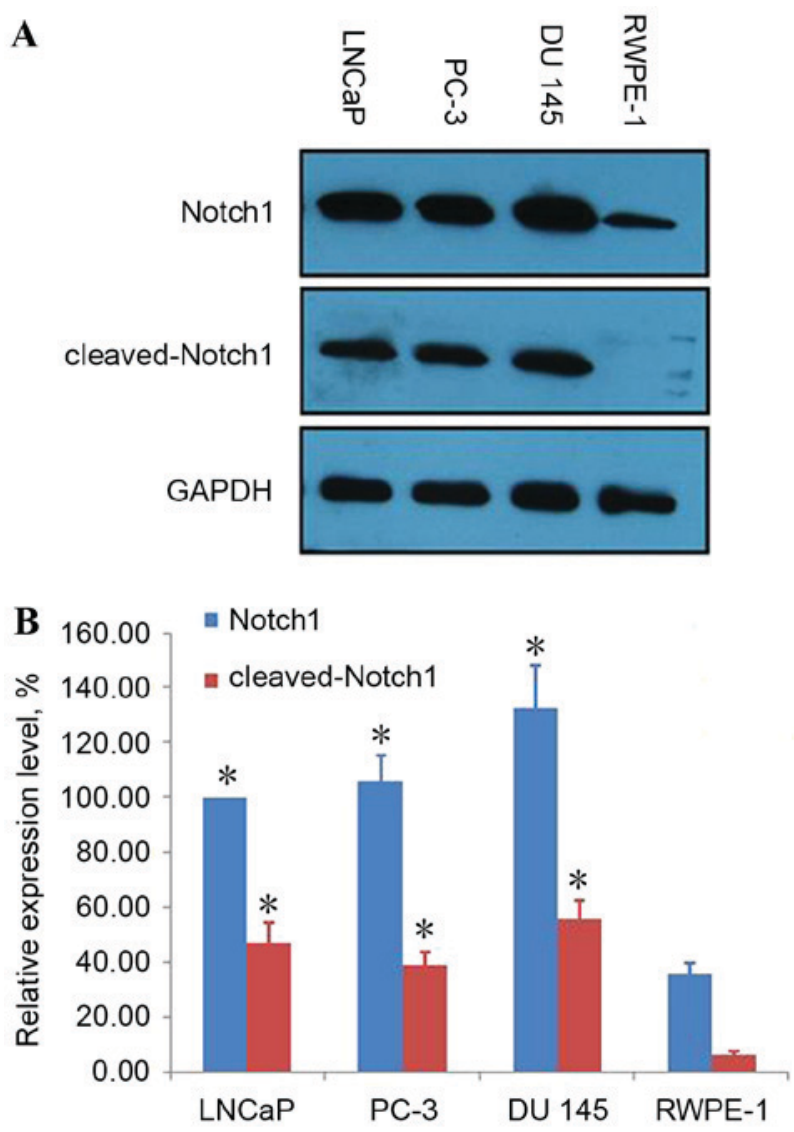

Figure 1. Notch1 and cleaved-Notch1 expression in the human prostatic carcinoma cell lines LNCaP, PC-3 and DU 145 and the immortalized human prostatic epithelial RWPE-1 cell line. (A) Western blot analysis. Total cell lysates were collected from LNCaP, PC-3, DU 145 and RWPE-1 cells, and analyzed for Notch1 and cleaved-Notch1 proteins. Anti-GAPDH antibody was included as a loading control. (B) Quantitative analysis for the changes of Notch1 and cleaved-Notch1 proteins. Intensity of the targeted protein/modification was normalized to corresponding GAPDH. Data represent the average results from three independent experiments. ${ }^{*} \mathrm{P}<0.05$ vs. RWPE-1 group.

LNCaP cells were subjected to cell invasion and proliferation assays. The invasion of Notch1-knockdown cells through the extracellular matrix was reduced compared with non-transfected cells or cells transfected with scrambled shRNA (Fig. 3A). Notch1-knockdown caused a 60\% decrease in cell invasion (Fig. 3B), indicating that Notch1 conferred invasive properties to $\mathrm{PCa}$ cells. In addition, the proliferation of Notch1-knockdown cells was significantly reduced $48 \mathrm{~h}$ post-transfection (Fig. 3C).

Notch1-knockdown changes the expression of genes involved in cell invasion. To define the mechanism of Notch1 in LNCaP cells invasion, RT-qPCR was performed on a number of invasion-associated genes. Notch1-knockdown resulted in a significant decrease in the expression of metastasis-associated 1 (MTA1) and increase of KiSS-1 metastasis-suppressor (KISS-1), mitogen-activated protein kinase 4 (MKK4) and cluster of differentiation 82 (KAI1) compared with non-transfected control cells or cells transfected with scrambled shRNA (Fig. 4). These results indicated that Notch1 may regulate the expression of these downstream target genes that are involved in extracellular matrix degradation, indicating that Notch1 may be involved in cell invasion. 


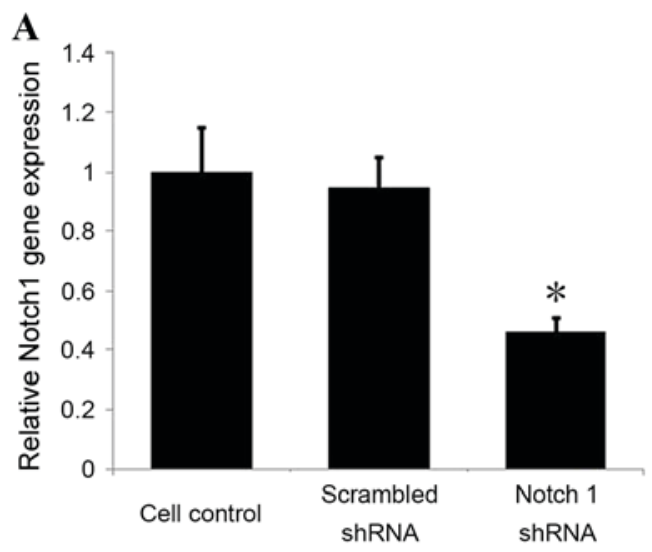

B

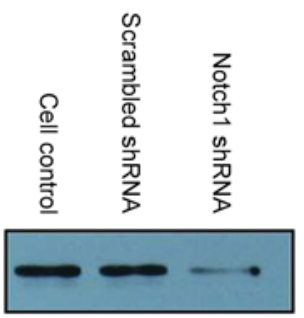

cleaved-Notch1

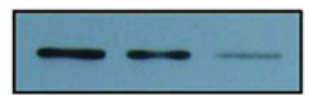

GAPDH
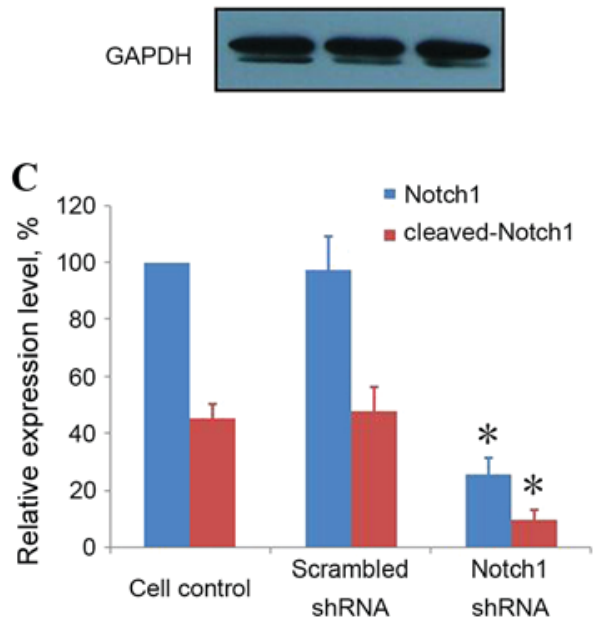

Figure 2. Knockdown of Notch1 by shRNA in LNCaP cells. (A) Reverse transcription-quantitative polymerase chain reaction and (B) western blot analysis of Notch1 mRNA and protein expression levels following transfection. (C) Quantitative analysis of Notch1 and cleaved-Notch1 protein levels. Intensity of the targeted protein and modification was normalized to corresponding GAPDH. Data represent the average results from three independent experiments. ${ }^{*} \mathrm{P}<0.05$ vs. control group. shRNA, short hairpin RNA.

\section{Discussion}

The Notch signaling pathway may be aberrantly activated, and contributes to the development, invasion and metastasis of a wide variety of human cancers, including cervical, lung, colon, head and neck, renal carcinoma, acute myeloid, Hodgkin and large-cell lymphomas and pancreatic cancer $(19,20)$. Notch1 has also been reported to be involved in the metastasis of tumors, including osteosarcoma, breast cancer, melanoma and prostate cancer (21-23). In spite of these findings, the involvement of Notch1, in particular aberrantly-activated Notch1 signaling in prostate cancer cell metastasis, requires
A
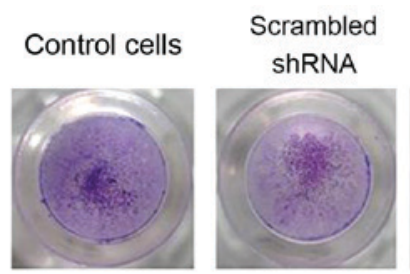

Notch1
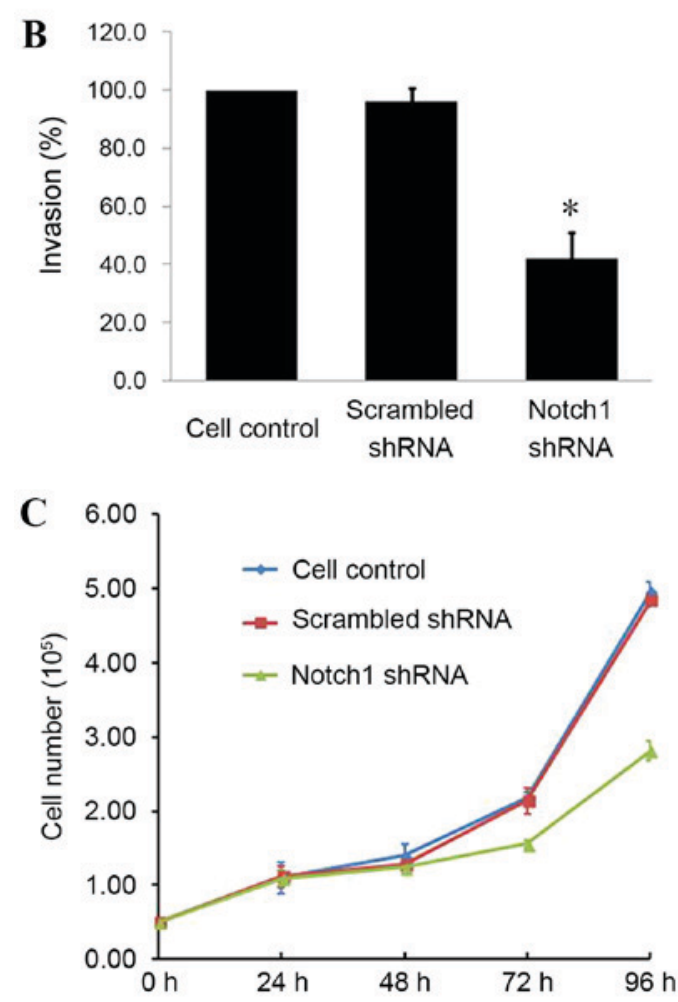

Figure 3. Effect of Notch1-knockdown on invasion and proliferation of LNCaP cells. (A) Results of the Matrigel invasion assay and (B) quantitative analysis. ${ }^{*} \mathrm{P}<0.05$ vs. control group. (C) Results of the cell proliferation assay, detected by WST-1 agent. Data represent the average results from three independent experiments. shRNA, short hairpin RNA.

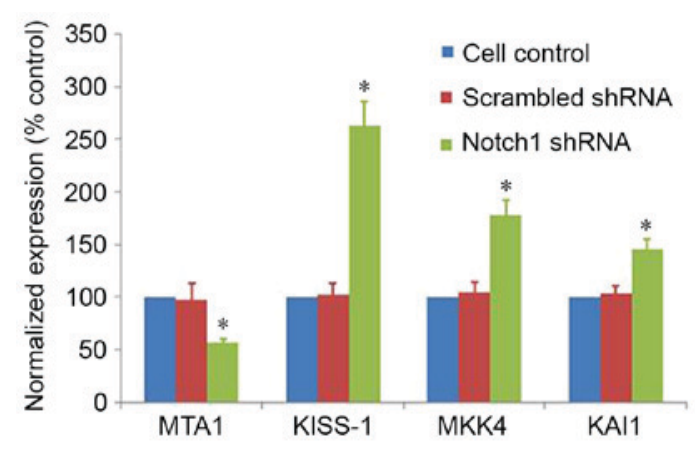

Figure 4. Effect of Notch1-knockdown on the expression of genes involved in cell invasion in LNCaP cells, assessed by reverse transcription-quantitative polymerase chain reaction. Data represent the average results from three independent experiments. ${ }^{*} \mathrm{P}<0.05$ vs. control group. MTA1, metastasis-associated 1; KISS-1, KiSS-1 metastasis-suppressor, MKK4, mitogen-activated protein kinase 4; KAI1, cluster of differentiation 82; shRNA, short hairpin RNA.

verification. In the present study, the activity of Notch-1 was investigated by shRNA-knockdown in human PCa LNCaP cells. Notch1 was revealed to be overexpressed in LNCaP, 
PC-3 and DU 145 cells compared with RWPE-1 cells, and cleaved-Notch1 was expressed in LNCaP, PC-3 and DU 145 cells, but not RWPE-1 cells. These results were consistent with the findings of Bin Hafeez et al (24), indicating that Notch signaling is involved in prostate cancer development. It was also observed that knockdown of Notch1 by shRNA in LNCaP cells markedly decreased cell invasion through Matrigel, which mimicked the in vivo extracellular matrix, and cell proliferation was also inhibited $48 \mathrm{~h}$ post-transfection. The reduction in migration, invasion and proliferation in PCa cells has been demonstrated to be associated with Notch1-knockdown by RNA interference (24-26). The present results verified the involvement of Notch1 in prostate cancer cell metastasis.

The present study revealed that the expression of MTA1 decreased significantly following RNA interference by Notch1 shRNA. MTA1 was initially identified in breast cancer (27), and was classified as a metastasis-associated protein. It exists primarily in the nucleus as a constituent part of the nucleosome remodeling and histone deacetylation complex (28). Subsequently, MTA1 was also detected in the cytoplasm (29).

Xue et al (30) reported that MTA1 exhibits a strong inhibitory activity for the transcription of a variety of tumor suppressor genes. MTA1 is a stress response protein (31). Multiple tumors have been confirmed to be associated with MTA1, including breast cancer and colorectal cancer (32). High expression levels of MTA1 may help cells to migrate to more hospitable areas in order to survive in adverse conditions, including hypoxia (33). An additional study has also indicated that overexpression of MTA1 is consistent with a more advanced tumor stage and increases the rate of metastasis (34). An increase of KISS-1, MKK4 and KAI1 was also observed in Notch1-knockdown cells, indicating that Notch1 may regulate the expression of MTA1, KISS-1, MKK4 and KAI1.

The present data demonstrated the involvement of Notch1 in human PCa invasion and that knockdown of Notch1 inhibited invasion of human PCa cells by downregulating the expression of MTA1 and upregulating the expression of KISS-1, MKK4 and KAI1. These findings indicated that targeting Notch1 may be a novel therapeutic approach for the treatment of prostate cancer metastasis.

\section{Acknowledgements}

The authors would like to thank Zhejiang Academy of Medical Sciences (Hangzhou, China) for expert technical assistance. This study was funded by the Natural Science Foundation of Zhejiang Province (Y2111329, LY13H310004, LY17H050002), the Science and Technology Plan Projects of Zhejiang Province (2014C37016), the National Natural Science Foundation of China (81172072), the Science Foundation for Distinguished Young Scholars of Zhejiang (R2101405), the Chinese Medicine Science and Technology Plan Projects of Zhejiang Province (2016ZB099, 2013ZA107, 2011ZB099), the Medicine and Health Science and Technology Plan Projects of Zhejiang Province (2011KYB066, 2015KYB295), the Science and Technology Plan Projects of Hangzhou (2017A05, 20110833B05, 20110733Q12), the Major Science and Technology Innovation Project of Hangzhou (20112313A01) and the Collaborative Innovation Projects of Science and Technology Department of Zhejiang Province (2014F50014).

\section{References}

1. Siegel RL, Miller KD and Jemal A: Cancer statistics, 2015. CA Cancer J Clin 65: 5-29, 2015.

2. Bubendorf L, Schöpfer A, Wagner U, Sauter G, Moch H, Willi N, Gasser TC and Mihatsch MJ: Metastatic patterns of prostate cancer: An autopsy study of 1,589 patients. Hum Pathol 31: 578-583, 2000.

3. Lawton A, Sudakoff G, Dezelan LC and Davis N: Presentation, treatment, and outcomes of dural metastases in men with metastatic castrate-resistant prostate cancer: A case series. J Palliat Med 13: 1125-1129, 2010.

4. B R and C GP: Path to facilitate the prediction of functional amino acid substitutions in red blood cell disorders - a computational approach. PLoS One 6: e24607, 2011.

5. Carvalho FL, Simons BW, Eberhart CG and Berman DM: Notch signaling in prostate cancer: A moving target. Prostate 74 : 933-945, 2014.

6. Vinson KE, George DC, Fender AW, Bertrand FE and Sigounas G: The notch pathway in colorectal cancer. Int J Cancer 138: 1835-1842, 2016.

7. Eliasz S, Liang S, Chen Y, De Marco MA, Machek O, Skucha S, Miele L and Bocchetta M: Notch-1 stimulates survival of lung adenocarcinoma cells during hypoxia by activating the IGF-1R pathway. Oncogene 29: 2488-2498, 2010.

8. Mumm JS and Kopan R: Notch signaling: From the outside in. Dev Biol 228: 151-165, 2000.

9. Wang Z, Li Y, Banerjee S and Sarkar FH: Exploitation of the Notch signaling pathway as a novel target for cancer therapy. Anticancer Res 28: 3621-3630, 2008.

10. Talora C, Campese AF, Bellavia D, Felli MP, Vacca A, Gulino A and Screpanti I: Notch signaling and diseases: An evolutionary journey from a simple beginning to complex outcomes. Biochim Biophys Acta 1782: 489-497, 2008.

11. Kopan R and Ilagan MX: The canonical Notch signaling pathway: Unfolding the activation mechanism. Cell 137: 216-233, 2009.

12. Hori K, Sen A and Artavanis-Tsakonas S: Notch signaling at a glance. J Cell Sci 126: 2135-2140, 2013.

13. Hudson BD, Kulp KS and Loots GG: Prostate cancer invasion and metastasis: Insights from mining genomic data. Brief Funct Genomics 12: 397-410, 2013.

14. Balint K, Xiao M, Pinnix CC, Soma A, Veres I, Juhasz I, Brown EJ, Capobianco AJ, Herlyn M and Liu ZJ: Activation of Notch1 signaling is required for beta-catenin-mediated human primary melanoma progression. J Clin Invest 115: 3166-3176, 2005.

15. Yeh TS, Wu CW, Hsu KW, Liao WJ, Yang MC, Li AF, Wang AM, Kuo ML and Chi CW: The activated Notch1 signal pathway is associated with gastric cancer progression through cyclooxygenase-2. Cancer Res 69: 5039-5048, 2009.

16. Negri FV, Crafa P, Pedrazzi G, Bozzetti C, Lagrasta C, Gardini G, Tamagnini I, Bisagni A, Azzoni C, Bottarelli L, et al: Strong Notch activation hinders bevacizumab efficacy in advanced colorectal cancer. Future Oncol 11: 3167-3174, 2015.

17. Ponnurangam S, Dandawate PR, Dhar A, Tawfik OW, Parab RR, Mishra PD, Ranadive P, Sharma R, Mahajan G, Umar S, et al: Quinomycin A targets Notch signaling pathway in pancreatic cancer stem cells. Oncotarget 7: 3217-3232, 2016

18. Lefort K, Ostano P, Mello-Grand M, Calpini V, Scatolini M, Farsetti A, Dotto GP and Chiorino G: Dual tumor suppressing and promoting function of Notch1 signaling in human prostate cancer. Oncotarget 7: 48011-48026, 2016.

19. Stylianou S, Clarke RB and Brennan K: Aberrant activation of notch signaling in human breast cancer. Cancer Res 66: $1517-1525,2006$.

20. Agrawal N, Frederick MJ, Pickering CR, Bettegowda C, Chang K, Li RJ, Fakhry C, Xie TX, Zhang J, Wang J, et al: Exome sequencing of head and neck squamous cell carcinoma reveals inactivating mutations in NOTCH1. Science 333: 1154-1157, 2011.

21. Leong KG, Niessen K, Kulic I, Raouf A, Eaves C, Pollet I and Karsan A: Jagged1-mediated Notch activation induces epithelial-to-mesenchymal transition through Slug-induced repression of E-cadherin. J Exp Med 204: 2935-2948, 2007.

22. Chen J, Imanaka N, Chen J and Griffin JD: Hypoxia potentiates Notch signaling in breast cancer leading to decreased E-cadherin expression and increased cell migration and invasion. Br J Cancer 102: 351-360, 2010.

23. Santagata S, Demichelis F, Riva A, Varambally S, Hofer MD, Kutok JL, Kim R, Tang J, Montie JE, Chinnaiyan AM, et al: JAGGED1 expression is associated with prostate cancer metastasis and recurrence. Cancer Res 64: 6854-6857, 2004. 
24. Bin Hafeez B, Adhami VM, Asim M, Siddiqui IA, Bhat KM Zhong W, Saleem M, Din M, Setaluri V and Mukhtar H: Targeted knockdown of Notch1 inhibits invasion of human prostate cancer cells concomitant with inhibition of matrix metalloproteinase-9 and urokinase plasminogen activator. Clin Cancer Res 15 452-459, 2009.

25. Zhang Y, Wang Z, Ahmed F, Banerjee S, Li Y and Sarkar FH: Down-regulation of Jagged-1 induces cell growth inhibition and $\mathrm{S}$ phase arrest in prostate cancer cells. Int J Cancer 119: 2071-2077, 2006.

26. Shou J, Ross S, Koeppen H, de Sauvage FJ and Gao WQ: Dynamics of notch expression during murine prostate development and tumorigenesis. Cancer Res 61: 7291-7297, 2001.

27. Toh Y, Pencil SD and Nicolson GL: A novel candidate metastasis-associated gene, mta1, differentially expressed in highly metastatic mammary adenocarcinoma cell lines. cDNA cloning, expression, and protein analyses. J Biol Chem 269: 22958-22963, 1994

28. Toh Y and Nicolson GL: The role of the MTA family and their encoded proteins in human cancers: Molecular functions and clinical implications. Clin Exp Metastasis 26: 215-227, 2009.
29. Liu J, Xu D, Wang H, Zhang Y, Chang Y, Zhang J, Wang J, Li C, Liu $\mathrm{H}$, Zhao M, et al: The subcellular distribution and function of MTA1 in cancer differentiation. Oncotarget 5: 5153-5164, 2014.

30. Xue Y, Wong J, Moreno GT, Young MK, Côté J and Wang W: NURD, a novel complex with both ATP-dependent chromatin-remodeling and histone deacetylase activities. Mol Cell 2: 851-861, 1998.

31. Li J, Ye L, Sun PH, Satherley L, Hargest R, Zhang Z and Jiang WG: MTA1 Is Up-regulated in colorectal cancer and is inversely correlated with lymphatic metastasis. Cancer Genomics Proteomics 12: 339-345, 2015.

32. Kang HJ, Lee MH, Kang HL, Kim SH, Ahn JR, Na H, Na TY, Kim YN, Seong JK and Lee MO: Differential regulation of estrogen receptor $\alpha$ expression in breast cancer cells by metastasis-associated protein 1. Cancer Res 74: 1484-1494, 2014.

33. Wang RA: MTA1-a stress response protein: A master regulator of gene expression and cancer cell behavior. Cancer Metastasis Rev 33: 1001-1009, 2014.

34. Luo H, Li H, Yao N, Hu L and He T: Metastasis-associated protein 1 as a new prognostic marker for solid tumors: A meta-analysis of cohort studies. Tumour Biol 35: 5823-5832, 2014. 